\title{
What is involved in forgiving?
}

\author{
PAUL M. HUGHES \\ Department of Humanities, University of Michigan, Dearborn, Dearborn, \\ MI 48128-3643, USA
}

\section{Introduction}

Philosophers have argued that forgiveness involves overcoming anger toward another who has done wrong, overcoming non-angry negative emotional states aimed at another who has done wrong, or (in addition to overcoming unhappy feelings) repudiating the belief that the wrongdoer remains a wrongdoer. ${ }^{1}$ My contention is that forgiveness typically involves overcoming moral anger toward another. Not all instances of anger constitute moral anger, and thus overcoming anger does not always constitute forgiveness. By moral anger I mean anger partially constituted by the belief that you have been wrongfully harmed by another. More precisely, "moral anger" is anger partially constituted by the belief that (1) you have been wrongfully harmed, or (2) you have been wrongfully put at the risk of harm, or (3) you have been or are the object of an intended wrongful harm or have been or are the object of an intended wrongful risk of harm. These complex qualifications are needed to fully articulate the possible constitutive beliefs of moral anger. The background theory I rely upon is the view that sophisticated emotions, such as resentment, pride, love, and shame, require specific identificatory beliefs the lack of which would render them unintelligible. ${ }^{2}$ Since resentment involves the belief that you have been wrongfully harmed, it is a central case of moral anger; thus, forgiveness will paradigmatically involve the overcoming of resentment. Other forms of anger count as moral anger just in case the belief that you have been wrongfully harmed is partially constitutive of them. Since negative emotional responses to wrongful harm, such as disappointment, heartbreak, or depression, do not necessarily involve this belief, and are often less focused than are angry emotions, forgiveness will typically involve overcoming moral anger rather than some other emotion. I will defend this approach to forgiveness, 
arguing in the process that recent alternative views fail to adequately articulate what is involved in forgiving.

\section{Resentment, moral agency, and overcoming moral anger}

In what sense must you have been harmed (or believe that you have been harmed) in order to experience moral anger toward another? Not just any harm will do, for moral anger is not always an appropriate response to having been harmed. Here I discuss resentment as the central case of moral anger, but I will show below that the argument applies as well to other instances of moral anger.

The number of ways in which a person may be harmed is limitless. A person may be killed, wounded, significantly inconvenienced, or otherwise harmed by a natural disaster, an animal, or another person. Yet to claim that people resent bad weather or destructive pets or whining infants is absurd. Notwithstanding the fact that people often claim to resent the harms caused by their pets, and parents sometimes resent their offspring because they represent an intolerable financial or emotional burden or serve as a reminder of a bad relationship, the correct view is that people can only resent moral agents. Animals, small children, mental incompetents, and natural events are not moral agents. This does not mean that we can only resent mature, mentally competent people. Nations, corporations, and other collectives, which are in some sense greater than the sum of their parts, may be moral agents in the relevant sense, and are therefore sometimes the appropriate objects of resentment. Nor does it mean that we cannot be angry in some other (non-moral) sense on account of the harms caused by animals, natural events, and other non-moral agents. The point is that just as we can only resent moral agents, so too moral anger of any sort must be directed at moral agents. The conception of moral agency at issue is quite simple: a moral agent is an agent to whom we can sensibly ascribe moral responsibility. This coincides with our intuition that resentment is a moral response to harm, while other forms of anger need not be. This accounts, as well, for our intuition that forgiveness, unlike other modes of overcoming anger, is a moral phenomenon; that is, when done for appropriate reasons it is a virtue.

But when is overcoming resentment (moral anger) forgiveness? Other writers have argued that overcoming resentment or forswearing negative feelings is forgiveness just in case it is done for a moral reason. There is truth in this suggestion, and we should clarify what is to count as a "moral" reason. But, independently of this issue, a question arises about the precise sense in which people must "overcome" resentment for the forswearing of 
such negative feelings to count as forgiveness.

Jeffrie Murphy argues that forgiveness is the virtue that helps keep resentment in check, yet that it is more than merely overcoming resentment. Murphy points out that we sometimes forget or "get bored with" our resentments, and in this way they dissipate. Forgetting or becoming bored with our resentments "just happens to us," and is hardly to be counted as a virtue, let alone the virtue of forgiveness. Moreover, other ways of being liberated from resentment, such as visiting a behavior-modification therapist in order to have our resentment "extinguished" (assuming for the sake of argument that this is possible), do not constitute forgiveness because forgiveness requires overcoming resentment "for a moral reason." But while forgetting resentments (where forgetting is entirely passive) is hardly the exercise of the virtue of forgiveness, neither is it a case of overcoming resentment in the relevant sense. The concept of "overcoming" is ordinarily associated with such notions as "conquering," "overpowering," "gaining the upper hand on," or "prevailing over"; these terms suggest selfactivity and effort. Paradigmatic examples of overcoming in this sense abound, as for instance when a person successfully overcomes a physical or mental handicap, or the debilitating psychological effects of an internalized stereotype, or the untoward consequences of social and economic injustice. These suggest that the concept of "overcoming" involves the notion of a person's getting beyond obstacles by her or his own efforts, or by the joint efforts of several people. Overcoming resentment presupposes effort or struggle on the part of s/he who overcomes. Forgetting is, however, a completely passive phenomenon, in the sense at issue, and so fails to be a case of overcoming anything at all.

This does not mean that overcoming resentment simpliciter is forgiveness. Murphy and other writers are correct in alluding to limits on what can count as cases of overcoming resentment that constitute forgiveness. The point these writers are making is that to forgive another is to struggle to overcome the anger born of having been wrongfully harmed. To forgive another is to engage in an internal drama: people struggle to overcome their resentment. This cannot be accomplished by anyone else (a surrogate forgiver, let us say), and its success admits of degrees. Passively to forget or have anger artificially excised does not involve the "moral work" necessary to forgive another. Forgiveness is an accomplishment; it is a mending of the moral fences between two persons and is the re-acceptance of another.

\section{Is forgiveness overcoming all negative feelings?}

That forgiveness is paradigmatically overcoming moral anger, of which 
resentment is the central case, does not show that it is only forswearing moral anger. Overcoming any negative emotional state, for example, disappointment or sorrow, caused by and directed toward a wrongdoer should perhaps count as forgiveness. In the following examples I clarify my position and address this alternative view of what might be called the "scope" of forgiveness.

Suppose Peter betrays Mary. Mary may respond by holding Peter in contempt, or by regarding him with disgust, or treating him scornfully. None of these emotional responses is resentment, the central case of moral anger. Yet we are inclined to think that were Mary to overcome (in the appropriate way) these emotional states directed at Peter she would thereby have forgiven him. On my account, overcoming such negative emotional states, if they are partially constituted by the belief that you have been wrongfully harmed, count as instances of forgiveness because they count as instances of overcoming moral anger. Thus, Mary's overcoming contempt or scorn for Peter is forgiveness.

Imagine instead that Mary resents Peter's having betrayed her. In struggling to overcome this negative emotional state Mary succeeds. Her resentment, however, is replaced by scorn. Rather than wishing to wring Peter's neck for what he has done, Mary feels that their friendship ought to be abandoned because it involves a fundamental lack of mutual respect. This is not a case of forgiveness, for Mary's emotional state subsequent to overcoming resentment is itself moral anger (namely, scorn) caused by Peter's wrongdoing.

Now suppose that Mary's emotional response to having been betrayed is disappointment or sadness rather than anger. A person may indeed overcome such negative emotional states (in the relevant sense of "overcome") and yet, on my view, this would not constitute forgiveness. This, we might argue, is counterintuitive. This last case suggests that forgiveness enjoys a much wider scope than I have allowed, and thus that my analysis is misguided.

Norvin Richards argues that forgiveness is overcoming any negative emotional state caused by and aimed at another who has done you wrong. For Richards the aforementioned example shows a need to expand the definition of forgiveness so that it may include overcoming "all negative feelings ... of whatever kind" aimed at the person who caused "the episode in question." While forgiveness may involve overcoming negative emotions other than anger, I challenge the notion that it requires overcoming all such emotions.

Anger admits of many varieties, including animosity, indignation, wrath, malice, contempt, and possibly disgust. This family of concepts, the "angry emotions," allows for instances of moral anger other than resentment just in 
case such emotions are partially constituted by the belief that you have been wrongfully harmed. In arguing that moral anger includes forms of anger other than resentment, and thus that overcoming these types of anger may count as forgiveness, I have urged that the distinction between "moral anger" and "non-moral anger" is crucial for sorting out genuine cases of forgiveness from other forms of overcoming anger. I suggest that a similar distinction be made with regard to negative emotions other than anger the overcoming of which (if appropriately qualified) may count as forgiveness. In this way, overcoming some negative emotions other than moral anger may qualify as forgiveness, though as I argue below other reasons suggest that this is rarely the case.

The belief that you have been wrongfully harmed is essential to the moral nature of forgiveness; without it, your emotional response to wrongdoing is morally obscure. While forms of anger other than resentment and, in general, other negative emotional states, may involve the belief that you have been wrongfully harmed, they need not. Where this belief is absent, overcoming those states can hardly constitute forgiveness, for there is nothing to forgive. Thus, overcoming non-angry negative emotions may constitute forgiveness if those emotions involve the belief that you have been wrongfully harmed. Yet overcoming frustration, heartache, depression, disappointment, misery, or unhappiness may not constitute forgiveness even when these emotional states involve the belief that you have been wrongfully harmed. This is so because these are emotional states that do not always have the requisite intentionality to focus on a wrongdoer. This is not to deny that such states may sometimes have "targets" (we can be disappointed in someone, or unhappy with another), just that the belief that you have been wrongfully harmed is less likely by itself to guarantee that such negative feelings as general depression, misery, heartache, or unhappiness are as focused or directed as are angry emotions. In other words, these feelings are often more diffuse and, like heartbreak and grief, must "run their course," but moral anger is not usually thought of as having a course to run.

These complications render overcoming negative emotional states other than moral anger less clearly genuine cases of forgiveness, since a response to mistreatment with sadness, disappointment, or heartbreak may not, even where they are constituted in part by the belief that you have been wrongfully harmed, be a change in a person's feelings for another, which is of the essence of forgiveness.

These differences between anger and other negative emotional states like sadness, disappointment, and heartbreak suggest that forgiveness need not involve overcoming all negative emotional states based upon a wrongdoer's misdeed. Moreover, forgiving another may be compatible with an abiding 
sense of disappointment or unhappiness caused by the wrongdoer. Sometimes people overcome their anger but remain disappointed in the wrongdoer or saddened by the fact that they could have been wronged in the first place. To suppose that such people have not forgiven those who have wronged them is to assume that forgiveness requires that we wipe the emotional slate clean, that we "feel" as if the misdeed were never committed. This strikes me as too restrictive a requirement of forgiveness, and Richards's account is mistaken to the extent that it implies such a requirement. The view I have been urging all along is closer to the truth of the matter: forgiveness is typically the overcoming of moral anger caused by the wrongdoing of another and constituted in part by the belief that you have been wrongfully harmed.

\section{Is forgiveness the forswearing of beliefs?}

The above remarks to the effect that not all negative feelings must be overcome for forgiveness to take place fail to address a related question, namely, must the belief that another is a wrongdoer be repudiated as well? Jean Hampton argues that overcoming both resentment and the judgment that another is a wrongdoer are necessary conditions of forgiveness. Hampton urges:

If ... a victim overcame resentment towards his wrongdoer for moral reasons (e.g., because he believed that festering resentment affected his ability to respond lovingly to other human beings) yet sustained the belief (held soberly, and not in anger) that his wrongdoer was a terrible person and one with whom he should not associate, we would not say that he had forgiven his wrongdoer, only that he was no longer angry at her. ${ }^{4}$

In other words, the definition of forgiveness as overcoming resentment for moral reasons is inadequate, for it does not allow us to distinguish forgiveness from other forms of morally motivated overcoming of resentment. Metaphors such as "bestowed upon," or "offered to," and even "asking for" forgiveness, imply that forgiveness is a transaction between two people, while other forms of overcoming anger need not be. Moreover, such metaphors as "to cover," "to lift up and carry away," and "to let go," when used to refer to the wrong that was done, are, according to Hampton, "metaphors for the forgiver's removal of sin from the wrongdoer," and these assume that forgiveness involves overcoming a "point of view," not merely a negative emotion such as resentment. The perspective that is overcome is a point of view within which the wrongdoer is seen as "the one who hurt me," while in the new perspective the wrongdoer is "liberated 
from his burden of moral debt." Hampton tells us that this liberation restores a relationship by putting two persons on an equal footing once again. Furthermore,

When the victim sends away the immoral action in the way that a creditor would absolve a debt, he no longer holds the immoral action against the wrongdoer (in the same way that a creditor would no longer hold the debt against the debtor) ${ }^{6}$

So Hampton's point is that forgiving involves overcoming a point of view in favor of another, different, point of view. This second perspective involves liberating the wrongdoer from a moral burden and absolving him or her of it. The point of view that is overcome

is the product of a judgement of the other as one's transgressor, so it seems that it is really this judgement which a victim must let go of if he is going to be able to welcome that person back into his life.

Thus, letting go of the judgment that the wrongdoer is a transgressor is, in addition to overcoming resentment, a necessary condition of forgiveness.

I do not think that forgiveness must involve renouncing the judgment of another as a wrongdoer. Overcoming a point of view may involve less than this and still be forgiveness, as the following considerations make clear. Forgiving and absolving from a debt are importantly disanalogous, for when creditors forgive debts their doing so eliminates the debt. Forgiving, however, does not eradicate the wrong that has been done, as is presupposed by the fact that forgiveness is compatible with punishment. A parent may forgive a child some wrongdoing and yet, consistently with forgiving, insist on punishing the child, perhaps for the child's own good or even because s/he deserves it. But punishing a debtor is incompatible with truly absolving him or her of debt. Thus, people need not forswear the judgment that they have been wrongfully harmed in order to forgive wrongdoers. The victim who overcomes anger yet retains the belief that she or he has been wronged and that therefore a continued association with the wrongdoer would be unwise may not have forgiven the wrongdoer. In the absence of further information we cannot know whether forgiveness has occurred in such cases. Our inability in such cases to distinguish forgiveness from other forms of morally motivated overcoming of resentment does not entail that the difference between them is a function of whether certain beliefs have been abandoned. To Hampton's question: "if forgivers never give up the idea that the action was wrong, how can they ever give up the view of the actor as a wrongdoer?" I answer that they need not do so. The question itself assumes that the belief that another has wronged you entails the belief that the actor is a wrongdoer. In one way, this is quite right. A wrongdoer is 
one who has committed a wrong act. In a quite different sense, a wrongdoer is one who commits wrong acts; who is, in other words, on balance a wrongdoer. But this judgment, which Hampton may be relying upon in her claim that forgiveness involves repudiating the belief that the other is a wrongdoer (a "terrible" person), is not entailed by the belief that another has wrongfully harmed one. Hence, forgiving another need not involve abandoning the belief that the other is a wrongdoer.

Hampton's purpose in stressing the need for overcoming both resentment and the judgment of the offender as a wrongdoer is to show that even this apparently stronger definition of forgiveness is inadequate, for it fails to express the "change of heart" involved in forgiveness. This is so, for the definition of forgiveness as overcoming resentment and forswearing the belief that the offender is a wrongdoer, even when done for moral reasons, does not enable us to distinguish forgiveness from the morally dubious phenomenon of condonation; an essential difference between these is that forgiveness involves a change of heart whereas condonation does not. Consider the following case:

A woman marries a man with a stern, rather rigid father who is getting on in years. The father comes to stay with the couple for a visit, and finds his daughter-in-law's conduct irritating, the food less than perfect, the house less than clean, the conversation rather dull; in small ways he makes it clear that he considers the daughter-in-law to blame for the imperfections in his son's house. Whatever the motivations for the old man's attacks, let us suppose that they are unfair and give pain to the daughter-in-law. However, her husband says to her: "Look, he is my father and we should be on good terms with him. I know you think he is behaving badly, but be good and forgive him so that family peace can be preserved." 8

Hampton claims that were the woman to "drop" her judgment that the father-in-law is a wrongdoer and overcome the accompanying resentment for moral reasons (for the sake of preserving family harmony) she would be condoning, not forgiving, the wrongful behavior of her father-in-law. Thus the definition of forgiveness as the morally motivated overcoming of resentment and forswearing the judgment of another as a wrongdoer is incomplete, for it leaves us unable to distinguish forgiveness from condonation.

If forgiveness does not require that we renounce the judgment that our transgressors are wrongdoers, then we have no difficulty in distinguishing forgiveness from condonation. Renouncing the judgment that a transgressor is a wrongdoer is necessary for the form of condonation at issue. One way a person condones the wrongdoing of others is when the person overcomes resentment toward them and abandons the belief that they are wrongdoers. 
But this is required neither of forgiveness nor of another form of morally motivated overcoming of resentment. Suppose the woman in the aforementioned scenario retains the belief that her father-in-law is a wrongdoer yet lets go of her resentment for moral reasons (for the sake of preserving family harmony). This may be a case of making the best of a bad situation. Accepting the fact that nothing can realistically be done about unpleasant circumstances need not be either forgiveness or condonation. I am at a loss as to what to call whatever people do when they do not condone and do not forgive, but surely there is middle ground here.

Hampton's view is complex and interesting, and many of the observations she makes about what she calls "moral hatred" are similar to what I have said here about "moral anger." One difference between her view and mine is that on her view overcoming the judgment of another as a wrongdoer is essential to forgiveness, while on my view it is not. Overcoming resentment for moral reasons may not be the whole story of forgiveness, but forswearing the belief that the offender is a wrongdoer is not among the missing elements.

\section{Conclusion}

I have argued that forgiveness paradigmatically involves overcoming moral anger, of which resentment is the central case. I have argued, as well, that forgiveness may involve overcoming any form of anger so long as the belief that you have been wrongfully harmed is partially constitutive of it, and that overcoming other negative emotions caused by a wrongdoer's misdeed may, given appropriate qualifications, count as forgiveness. Those qualifications indicate, however, significant differences between moral anger and other negative emotions; differences which must be taken into account when determining whether overcoming negative emotions other than moral anger count as forgiveness. I have proposed, too, that forgiveness requires neither overcoming all negative feelings (other than moral anger) nor the judgment that the offender is a wrongdoer.

I must acknowledge that my analysis is incomplete, focusing as it does on the forgiver rather than on the person forgiven. After all, there are two sides to forgiveness. Not all forgiving involves a struggle to overcome negative feelings; sometimes it is a social transaction of a more casual sort that is effected by the simple speech act "I forgive you." My analysis is incomplete insofar as it treats exclusively of forgiveness as a process and fails to offer an analysis of forgiveness as an act. Finally, a complete theory of forgiveness requires an account of the conditions under which forgiveness qualifies as a moral virtue, and such an account is beyond the scope of 
this essay. Though I have not offered a complete theory of forgiveness, my effort to clarify a dimension of what is involved in a common type of forgiveness may clear the way for answering related questions about it, and thereby lead to a fuller account of forgiveness as a moral phenomenon.

\section{Notes}

1. The view that forgiveness involves overcoming a specific type of anger toward another is maintained by Bishop Butler and shared by Howard McGary and Jeffrie G. Murphy. See Butler, "Upon Forgiveness of Injuries," in The Work of the Right Reverend Father in God, Joseph Butler, D.C.L., Late Bishop of Durham, ed. Samuel Halifax (New York: Carter, 1846); Howard McGary, "Forgiveness," American Philosophical Quarterly 26.4 (October 1989): 343-350; Jeffrie G. Murphy, "Forgiveness and Resentment," Midwest Studies in Philosophy, 7, ed. Peter French, Theodore Uehling, and Howard Wettstein (Minneapolis, University of Minnesota Press, 1982), p. 504; Murphy, "Forgiveness, Mercy, and the Retributive Emotions," Criminal Justice Ethics 7.2 (1988): 3-14; and Jeffrie G. Murphy and Jean Hampton, Forgiveness and Mercy (Cambridge, England: Cambridge University Press, 1988). The view that forgiveness involves overcoming negative feelings other than anger is advanced by Norvin Richards in "Forgiveness," Ethics 99 (October 1988): 77-97. For the view that particular beliefs must be renounced see Murphy and Hampton, Forgiveness and Mercy.

2. For more on such a theory see Gabriele Taylor, Pride, Shame, and Guilt: Emotions of Self-Assessment (Oxford: Oxford University Press, 1988).

3. As Murphy puts it, "Forgiveness is not the overcoming of resentment simpliciter; it is rather this: to forswear resentment on moral grounds," see "Forgiveness and Resentment," p. 128. This point is stressed as well in "Forgiveness, Mercy, and the Retributive Emotions," and by Murphy and Hampton in Forgiveness and Mercy. Compare McGary, "Forgiveness," p. 344: "Most accounts of forgiveness require the intentional cessation of resentment as a necessary condition for forgiveness ... [and] there are very specific ways that the resentment must cease to exist in order to satisfy this necessary condition of forgiveness."

4. Hampton, Forgiveness and Mercy, p. 36.

5. Ibid., p. 37.

6. Ibid., p. 38.

7. Ibid.

8. Ibid., p. 39 . 